\title{
Physician Trading Cards as a Tool to Improve Pediatric Resident Joy in Medicine while Improving Patient Satisfaction
}

\author{
Lindsay Weiss, $\mathrm{MD}^{{ }^{*}}$, Mary Edmond, $\mathrm{PhD}^{2}$, Sarah Varghese, $\mathrm{MD}^{2,3}$, Anthony Cooley, MD ${ }^{2,3}$
}

\begin{abstract}
Introduction: To combat resident physician burnout, wellness programming should include approaches that foster joy to work as a physician. Photograph trading cards have been used to improve patient satisfaction but have not been explored as a way to improve physician work satisfaction. We aimed to use trading cards to improve resident physician identification by patients' families, as well as measure their effect on the hospital experience for patients and residents.

Methods: For a one-month period in 2019, trading cards were piloted with the nine residents assigned to the inpatient pediatrics service. Employing five-point Likert scales, surveys were administered to residents and convenience samples of 100 patients' families before and after card distribution.

Results: Compared to families prior, those given trading cards reported increased perceived importance of physician identification and a greater association with care satisfaction. Families' ability to identify treating physicians increased from $5 \%$ to $66 \%$ with card distribution $(\mathrm{p}<0.0001)$. All 9 residents participated $(100 \%$ response rate). With the aid of this intervention, all residents either "strongly agreed" or "agreed" that they were better recognized as the physician. One hundred percent of residents "strongly agreed" or "agreed" with the statement "I find joy at work," compared to 77\% prior to intervention. At project completion, 88\% either "strongly agreed" or "agreed" trading cards improved work satisfaction. After using trading cards, residents articulated expressions of empowerment to deliver better care, enhancement of physician-patient communication, and improvement of patient experiences.
\end{abstract}

DOI: 10.18297/jwellness/vol3/iss1/3

Received Date: July 17, 2020 Revised Date: Nov 5, 2020 Accepted Date: Jan 182021 Publication Date: Feb 10, 2021 Website: https://ir.library.louisville.edu/ jwellness/

Recommended Citation: Weiss, Lindsay; Edmond, Mary; Varghese, Sarah; and Cooley, Anthony (2021) "Physician Trading Cards as a Tool to Improve Pediatric Resident Joy in Medicine while Improving Patient Satisfaction" Journal of Wellness: Vol. 3 : Iss. 1, Article 3.

Affiliations: 'Joe DiMaggio Children's Hospital, ${ }^{2}$ Children's Healthcare of Atlanta, 'Department of Pediatrics, Emory University

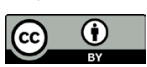

Conclusion: Trading cards can be used as a tool to improve resident physician work satisfaction and joy in medicine, while also improving the hospital experience for patients and families.

\section{INTRODUCTION}

As an effort to improve the hospital experience and patient satisfaction, some institutions have used photo "trading cards" to help patients identify their physicians. Studies show that patients frequently have difficulty identifying their hospital care team members and the use of trading cards can improve recognition [1-6]. Additionally, a randomized controlled trial by Brener et al. found this also improved impressions of teamwork effectiveness [1]. Other studies have demonstrated that patients believe their ability to identify their physicians facilitated both trust and satisfaction $[5,7,8]$. Moreover, the distribution of photographs of residents improved patient acceptance of the trainee involvement in their child's care [5, 9].

Physician burnout has reached epidemic numbers with $39-69 \%$ of residents reporting symptoms early in training $[10,11,12]$. Burnout is associated with increased depression and medical errors $[12,13]$. Misidentification of residents as non-physicians could contribute to burnout symptoms. According to identity negotiation theory, psychological coherence from social validation of self-identity is integral to wellbeing. When valued identities are not affirmed, emotional distress, a known correlate of burnout, is likely [14].

The American Council for Graduate Medical Education (ACGME) Physician Wellbeing Initiative has "the ultimate goal of reducing burnout and helping physicians rediscover joy and meaning in work" [15]. Common Program Requirements promote a culture of wellness [16]. Numerous studies have

*Correspondence To: Lindsay Weiss

Email: liweiss@mhs.net assessed reductions in burnout rates as a measure of physician wellness. However, few have measured joy and meaning in work.

To our knowledge, the impact of trading cards on physician work satisfaction has not been studied. We describe a single institution's experience piloting the use of trading cards with pediatric resident physicians.

Our objectives for this project were as follows:

1. To use trading cards to improve resident physician identification by patients and families

2. To measure the influence of trading cards on the patient and family experience

3. To assess the effect of trading cards on physicians' joy at work

\section{METHODS}

Participation was offered to all nine resident physicians assigned to the inpatient pediatrics service during this one-month pilot in 2019. Trading cards were printed for participating residents, who then gave their cards to patients and families during initial encounters (Figure 1, see next page).

We developed a 5-point Likert scale survey to be administered to residents, and another to survey families (Appendix A). These two surveys were created based on the authors' experience with residents who reported failure to be identified 


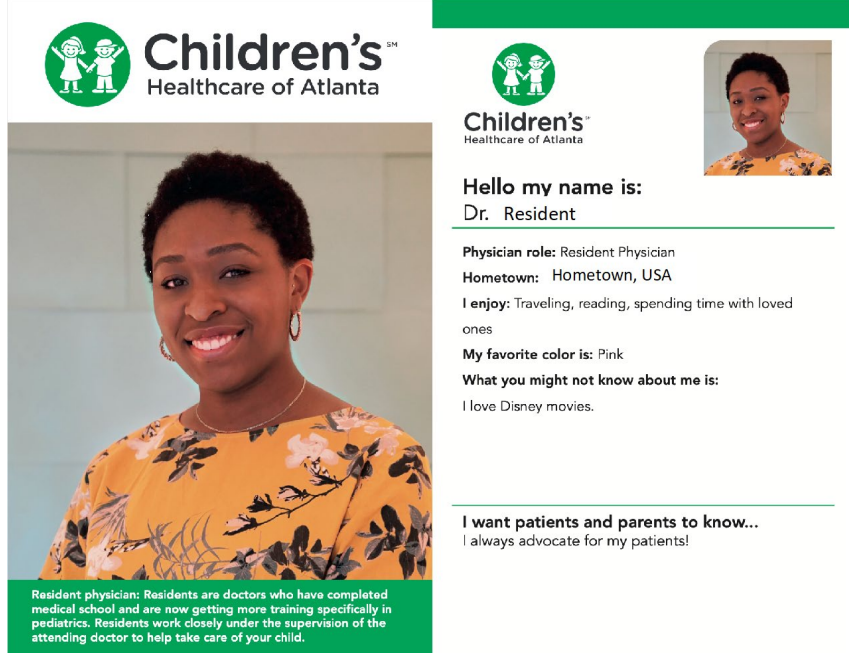

Figure 1: Trading Card Example

correctly as a physician or by name. Questions about joy at work and meaningful work were similar to previous surveys on workplace wellbeing and reflect ACGME expectations to foster well-being $[15,16]$. Pre-intervention surveys were completed on the first day of the ward rotation and post-intervention surveys were completed at the end of the four-week rotation; all surveys were anonymous and stored in RedCap. Residents were advised that the intent of this project was to improve their identifications as treating physicians. They were not told of any intent to improve joy or meaningfulness. Our questions for families were added to routine surveys conducted by our family experience representative. Utilizing convenience sampling, 100 families were interviewed for one month before and another 100 during distribution of trading cards. Among the questions, families were asked to identify the physicians by name (not description).

Our project proposal was submitted to Children's Healthcare of Atlanta Internal Review Board, who determined that this did not require additional review.

\section{Analysis}

Data analysis was completed in Stata-16 (StataCorp. 2019. Stata Statistical Software: Release 16. College Station, TX: StataCorp LLC) and consisted of basic descriptive information of the proportion of residents and patient families answering positively to each survey question in the pre- and post-intervention samples. Because the sample of resident respondents was quite small $(\mathrm{N}=9)$, no statistical tests beyond the proportional descriptions were applied to the resident surveys.

The patient family data was also described via proportional descriptions, but in addition, a simple statistical test was applied to assess the proportion of families able to identify their treating physicians in the pre-intervention sample compared to the post-intervention sample. The samples were unpaired and expected cell frequency was larger than five, so a chi-square test of association was used.

\section{RESULTS}

Each convenience sample contained 100 families who were surveyed pre- and post-distribution. The survey results showed changes before and after the trading card introduction in three self-reported dimensions: perceived importance of physician identification, association between physician identification and care satisfaction, and ability to identify treating physicians. Pre-intervention $20 \%$ of families reported it was "very important" for them to be able to identify the treating physician; whereas post-intervention: this rose to $29 \%$. Similarly, 19\% of families pre-intervention reported that accurate identification affected their satisfaction "a great deal," while $29 \%$ attested to this post-intervention. Finally, the proportion of families able to name their treating physician substantially increased from $5 \%$ pre-intervention to $66 \%$ post-intervention (chi-square result $=81.25 ; \mathrm{p}$-value $<0.0001$ ).

All nine residents (six women and three men) assigned to the inpatient pediatrics service participated in this voluntary pilot and completed pre- and post-surveys with a $100 \%$ response rate. Resident demographics are displayed in Figure 2.

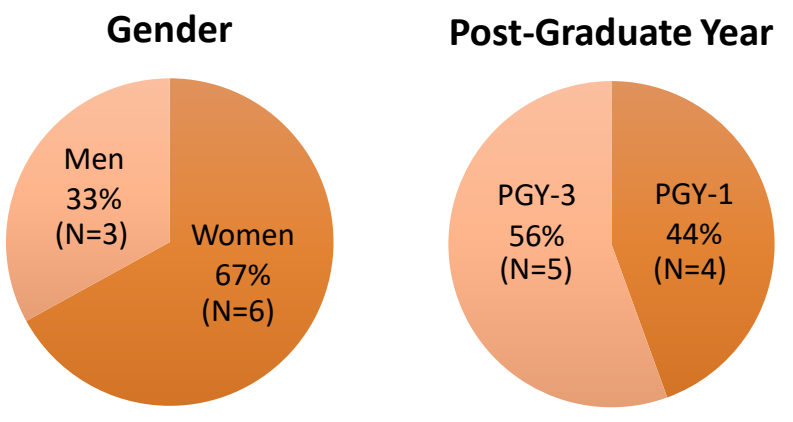

Figure 2: Resident Demographics

The residents distributed trading cards to their patients during the one-month intervention. Pre-intervention, fewer women reported that they were recognized as the treating physician. Specifically, none of the women reported that they were "always" recognized as the treating physician, and only two of the six women (33\%) reported that they were recognized "most of the time." In contrast, all three of the men reported that they were appropriately identified "always" or "most of the time."

After trading card distribution, all residents either "strongly agreed" or "agreed" that using trading cards improved families' ability to recognize them as the physician. Specifically, five of the six women (83\%) reported recognition as the treating physician "most of the time." Excepting for a single resident, physicians either "strongly agreed" (25\%) or "agreed" (63\%) that trading cards improved work satisfaction. After the project, $100 \%$ of residents "strongly agreed" (63\%) or "agreed" (37\%) with the statement "I find joy at work." Prior to this, $77 \%$ of the residents either "strongly agreed" (44\%) or "agreed" (33\%) with this statement (Figures 3, 4 \& 5 - next two pages).

Qualitative results of the study included physician comments that articulate the project's impact. Commonly expressed themes included empowerment to deliver better care, improved physician-patient communication, and improved patient experience as follows:

1. "Using trading cards is empowering because it helps families place trust in their team. They know who is taking care of them and that they are a physician. This helps me because it helps reinforce that I am capable."

2. "Patients take greater interest in listening and asking questions. I feel more of a connection with my patients."

3. "[This] showed me how much value I place on being identified correctly. So, in the future, I will make more of an effort to clarify my role with families."

4. "I have multiple patients' parents who thought the trading cards are absolutely wonderful. It helped them to remember our names and that we were part of the pediatric team. One mom told me that it made her feel more relaxed and closer to us." 

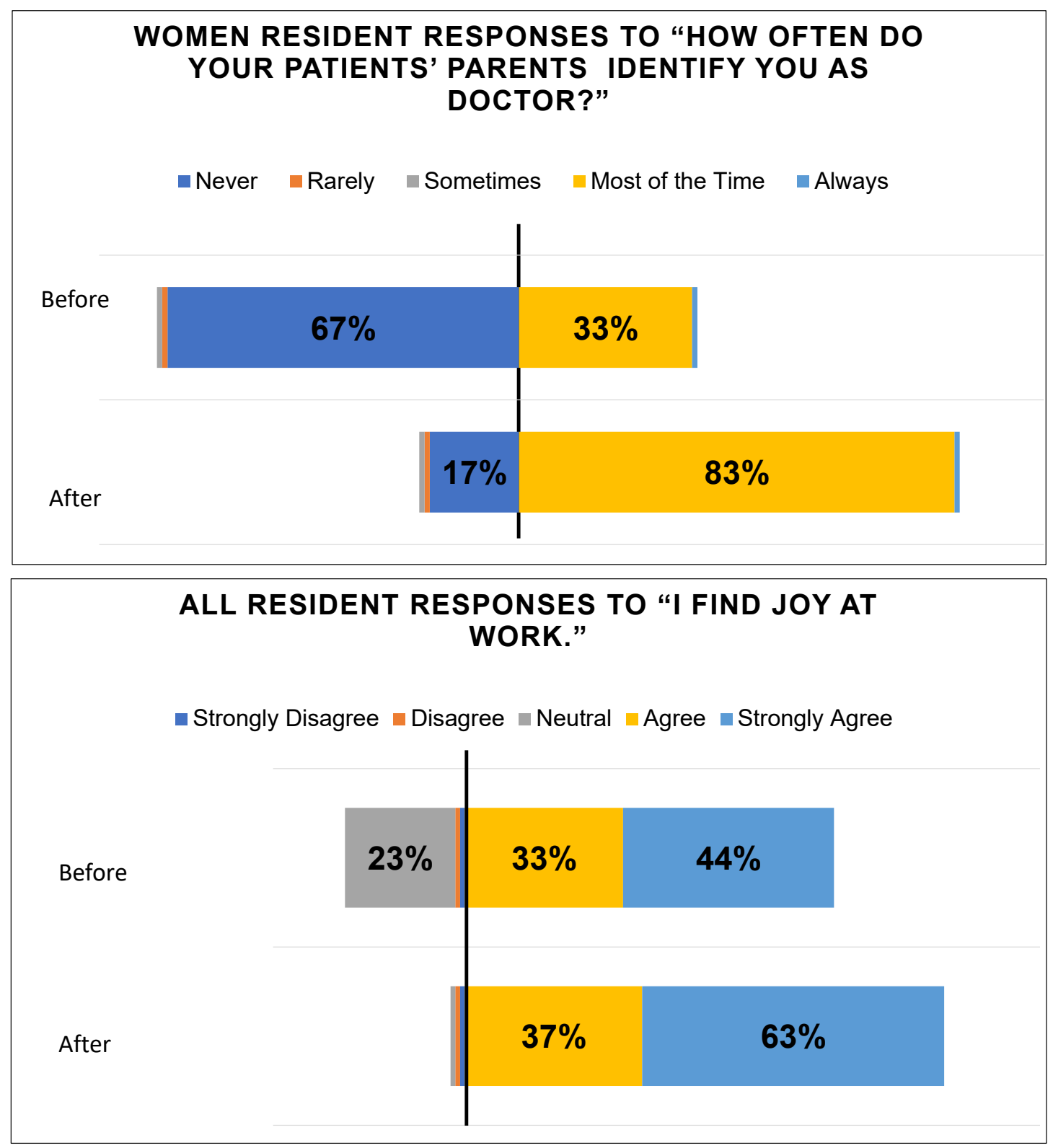

Figures 3-4: Survey Responses for Residents

\section{DISCUSSION}

We found an association with trading card use and improved patient and physician satisfaction. To our knowledge, this is the first study to find an intervention that fosters physician wellbeing while also improving the hospital experience for patients.

With resident burnout symptoms occurring at alarming rates, programs are challenged to identify wellness interventions to mitigate this. Trading cards may be one contributor to the solution-given the observed improvement in resident satisfaction and joy at work. Additionally, there was increased recognition of residents as treating physicians (especially for the female residents responding to our survey). Qualitative comments suggest that proper role identification may have improved the physician experience. Increasingly, imposter syndrome's role in burnout and its disproportionate effect on women has been acknowledged in many professions, including medicine $[17,18,19]$. Although we did not investigate imposter syndrome specifically, its role may be inferred by one woman's comment that this endeavor made her feel more capable.

With encouraging initial results, this pilot incentivizes funding cards for all pediatric residents at our hospital in the future. A larger-scale project would test the reproducibility of our findings and explore the effect of added factors such as physician gender and race on physician identification. Effect of the trading cards on resident burnout and imposter syndrome could be explored with more detailed questionnaires. Surveys could query burnout and connectivity to patients in addition to joy and meaning at work. Well-received by families, trading cards are easily handled by children, allow for a tactile connection and a keepsake from their encounter with their doctors. Business cards may serve as a more affordable option, but the smaller size would limit information that can be included. The size of trading cards allows for additional space for more personal biographical information, which may appeal to our younger patients. 


\begin{tabular}{|c|c|c|c|c|c|c|c|}
\hline Before & Neutral & Agree & $\begin{array}{l}\text { Strongly } \\
\text { Agree }\end{array}$ & After & Neutral & Agree & $\begin{array}{c}\text { Strongly } \\
\text { Agree }\end{array}$ \\
\hline All women & $33 \%(N=2)$ & $33 \%(N=2)$ & $33 \%(N=2)$ & All women & 0 & $33 \%(N=2)$ & $67 \%(N=4)$ \\
\hline PGY-1 & 0 & $67 \%(N=2)$ & $33 \%(\mathrm{~N}=1)$ & PGY-1 & 0 & 0 & $100 \%(\mathrm{~N}=3)$ \\
\hline PGY-3 & $67 \%(N=2)$ & 0 & $33 \%(N=1)$ & PGY-3 & 0 & $67 \%(N=2)$ & $33 \%(N=1)$ \\
\hline All men & 0 & $33 \%(N=1)$ & $67 \%(N=2)$ & All men & 0 & $33 \%(N=1)$ & $67 \%(N=2)$ \\
\hline PGY-1 & 0 & 0 & $100 \%(\mathrm{~N}=1)$ & PGY-1 & 0 & $100 \%(\mathrm{~N}=1)$ & 0 \\
\hline PGY-3 & 0 & $50 \%(\mathrm{~N}=1)$ & $50 \%(N=1)$ & PGY-3 & 0 & 0 & $100 \%(\mathrm{~N}=2)$ \\
\hline
\end{tabular}

Figure 5: Resident Responses by Gender and Post-Graduate Year: "I find joy at work."

\section{LIMITATIONS}

Our project was limited by its small number of participants. Funding only allowed a one-month pilot. Due to small sample size over a short study period, significant analyses of how physician sex or race may factor is limited. We specifically did not query about imposter syndrome, increasingly recognized as coexistent with burnout symptoms. Because of this group's excitement to participate, volunteer bias may have contributed positive skew.

\section{CONCLUSION}

Resident physicians reported improved work satisfaction, and greater joy in medicine with the distribution of trading cards to patients and families. Trading cards are a unique strategy to improve the healthcare experience for both the healer and healed.

\section{Acknowledgements}

We would like to acknowledge the Children's Healthcare of Atlanta Family Experience team for their assistance in development. Claire Aikens Doughtie is a Family Experience Learning Specialist, who conceptualized and helped produce the trading cards. Linda Perry is a Family Experience Liaison, who surveyed participating families.

\section{REFERENCES}

1. Brener MI, Epstein JA, Cho J, Yeh HC, Dudas RA, Feldman L. Faces of all clinically engaged staff: a quality improvement project that enhances the hospitalised patient experience. Int J Clin Pract. 2016 Nov;70(11):923-9.

2. Arora VM, Schaninger C, D’Arcy M, Johnson JK, Humphrey HJ, Woodruff JN, et al. Improving inpatients' identification of their doctors: use of FACE cards. Jt Comm J Qual Patient Saf. 2009 Dec;35(12):613-9.

3. Appel L, Abrams H, Morra D, Wu RC. Put a face to a name: a randomized controlled trial evaluating the impact of providing clinician photographs on inpatients' recall. Am J Med. 2015 Jan;128(1):82-9.

4. Simons Y, Caprio T, Furiasse N, Kriss M, Williams MV, O'Leary KJ. The impact of facecards on patients' knowledge, satisfaction, trust, and agreement with hospital physicians: a pilot study. J Hosp Med. 2014 Mar;9(3):137-41.

5. Dudas RA, Lemerman H, Barone M, Serwint JR Jr. PHACES (Photographs of Academic Clinicians and Their Educational Status): a tool to improve delivery of family-centered care. Acad Pediatr. 2010 Mar-Apr;10(2):138-45.

6. Unaka NI, White CM, Sucharew HJ, Yau C, Clark SL, Brady PW. Effect of a face sheet tool on medical team provider identification and family satisfaction. J Hosp Med. 2014 Mar;9(3):186-8.

7. Singh A, Rhee KE, Brennan JJ, Kuelbs C, El-Kareh R, Fisher ES. Who's my doctor? using an electronic tool to improve team member identification on an inpatient pediatrics team. Hosp Pediatr. 2016 Mar;6(3):157-65.

8. Francis JJ, Pankratz VS, Huddleston JM. Patient satisfaction associated with correct identification of physician's photographs. Mayo Clin Proc. 2001 Jun;76(6):604-8.

9. Berg DD, Divakaran S, Stern RM, Warner LN. Fostering meaning in residency to curb the epidemic of resident burnout: recommendations from four chief medical residents. Acad Med. 2019 Nov;94(11):1675-8.

10. Baer TE, Feraco AM, Tuysuzoglu Sagalowsky S, Williams D, Litman HJ, Vinci RJ. Pediatric resident burnout and attitudes toward patients. Pediatrics. 2017 Mar;139(3):e20162163.

11. Holmes EG, Connolly A, Putnam KT, Penaskovic KM, Denniston CR, Clark LH, et al. Taking care of our own: a multispecialty study of resident and program director perspectives on contributors to burnout and potential interventions. Acad Psychiatry. 2017 Apr;41(2):159-66.

12. Brunsberg KA, Landrigan CP, Garcia BM, Petty CR, Sectish TC, Simpkin AL, et al. Association of pediatric resident physician depression and burnout with harmful medical errors on inpatient services. Acad Med. 2019 Aug;94(8):1150-6.

13. Kang EK, Lihm HS, Kong EH. Association of intern and resident burnout with self-reported medical errors. Korean J Fam Med. 2013 Jan;34(1):36-42.

14. Swann WB Jr, Johnson RE, Bosson JK. Identity negotiation at work. Res Organ Behav. 2009;29:81-109.

15. ACGME. Improving physician well-being, restoring meaning in medicine. https://www.acgme.org/ 
What-We-Do/Initiatives/Physician-Well-Being. Published 2020.

16. ACGME. Common program requirements (residency). https://www.acgme.org/Portals/0/PFAssets/ProgramRequirements/CPRResidency2020.pdf

17. Bravata DM, Watts SA, Keefer AL, Madhusudhan DK, Taylor KT, Clark DM, et al. Prevalence, predictors, and treatment of imposter syndrome: a systematic review. J Gen Intern Med. 2020 Apr;35(4):1252-75.
18. Oriel K, Plane MB, Mundt M. Family medicine residents and the impostor phenomenon. Fam Med. 2004 Apr;36(4):248-52.

19. Villwock JA, Sobin LB, Koester LA, Harris TM. Impostor syndrome and burnout among American medical students: a pilot study. Int J Med Educ. 2016 Oct;7:364-9. 
Appendix A. Survey Questions

Survey of Patients and Families

Q: Who is your doctor? Free text

Q: How important is it to you to be able to identify your doctors treating you?

Not important

Slightly important

Moderately important

Important

Very important

Q: How much does your ability to identify the primary treatment team affect your satisfaction with your child's care?

Never

Little

Somewhat

Much

A great deal

Survey of Resident Physicians

Q: What is your role?

Senior Resident

Intern

Attending

Q: What is your gender?

Man

Women

Other (specify)

Prefer not to answer

Q: How often do your patients' parents identify you as doctor?

Never

Rarely

Sometimes

Most of the Time

Always

Q: Do you agree or disagree with the following statement: It is important to me that my patients' parents recognize me as a physician?

Strongly disagree

Disagree

Neutral

Agree

Strongly agree

Q: Do you agree or disagree with the following statement: It is important to me that my patients' parents recognize me by name?

Strongly disagree

Disagree

Neutral

Agree

Strongly agree

Q: Do you agree or disagree with the following statement: The ability of patients' parents to identify my role as physician impacts my work satisfaction?

Strongly disagree

Disagree

Neutral

Agree

Strongly agree 
Q: How do you most often introduce yourself to patients and their parents?

First name only

First \& Last name

Dr. [First \& Last name]

Dr. [Last name only]

Other (please specify)

Q: How do you most often introduce yourself to nurses?

First name only

First \& Last name

Dr. [First \& Last name]

Dr. [Last name only]

Other (please specify)

Do you agree or disagree with the following statements?

Q: The work I do is meaningful to me

Strongly disagree

Disagree

Neutral

Agree

Strongly agree

Q: I find joy at work

Strongly disagree

Disagree

Neutral

Agree

Strongly agree

Please rate your enthusiasm to practice medicine on a scale from 1 to 5 (with 1 being no enthusiasm and 5 being lots of enthusiasm)
1
2
3
4
5

Questions added post-intervention:

Q: Do you agree or disagree with the following statements?

Q: Using trading cards has improved my patients' parent's ability to recognize me as a physician: Strongly disagree

Disagree

Neutral

Agree

Strongly agree

Q: Because my patients' parents can use trading cards to better recognize me as the physician, my work satisfaction has improved:

Strongly disagree

Disagree

Neutral

Agree

Strongly agree

Please comment on how using trading cards has affected your identity as physician.

Free text

Please comment how being identified as a physician impacts your joy and meaning at work.

Free text 